\title{
Effect of Calcium and Magnesium Addition on the Cast Microstructure of HSLA Steel
}

\author{
Yan LIU ${ }^{1, a,{ }^{*}, \text { Kai WANG }}{ }^{2, b}$, Yang LIU ${ }^{2, c}$, Jian-Ming WANG ${ }^{2, d}$ \\ ${ }^{1}$ The Liaoning Provincial Key Laboratory of Advanced Materials \& Preparation Technology, \\ Shenyang University, Shenyang, 110044, China \\ ${ }^{2}$ School of Mechanical Engineering, Shenyang University, Shenyang 110044, China \\ aliuyanneu@163.com, bwkai1991@foxmail.com, cshendacaijialy@126.com, \\ wjmlucky1979@163.com \\ ${ }^{*}$ Corresponding author
}

Keywords: Calcium, Magnesium, Cast Microstructure, HSLA Steel.

\begin{abstract}
Using the oxide of high melting-point and high stability to pin the grain boundaries is an effective method to improve the welding performance of the HSLA steel in this study. A kind of HSLA steel is designed in this experiment. The thermal stability second phase particles which would not be dissolved or aggregated at high temperature will be expected by means of adding calcium and magnesium simultaneously into the steel in the form of $\mathrm{Si}-\mathrm{Ca}$ alloy and $\mathrm{Mg}-\mathrm{Zr}$ alloy. The effect of calcium and magnesium addition on the cast microstructure and inclusions of HSLA steel were analyzed. The results show that the cast microstructure is mainly consist of lamellar and acicular ferrite, a small amount of pearlite and bainite. Compared with the original steel, there are bainites presenting in the experimental steel after adding $3 \mathrm{wt} \% \mathrm{Ca}$ and $3 \mathrm{wt} \% \mathrm{Mg}$ at the same time.
\end{abstract}

\section{Introduction}

When the steel plates use the high heat input welding, the strength and toughness of the welding heat affected zone (HAZ) decreases with the increase of the heat input welding [1]. Using the oxide of high melting-point and high stability to pin the grain boundaries is an effective method to improve the welding performance of the structure steel. If this method combines with TMCP (Thermo Mechanical Control Process), we can get the high heat input welding high-strength low alloy (HSLA) steel, which has good toughness and weldability. This is a technology whereby thermally stable oxides and sulfides containing calcium and magnesium are dispersed in steel as fine particles in this study. Calcium and magnesium inclusions have high temperature stability, high melting point, ultra-fine, evenly distributed and controllable composition [2].

The experiment takes a kind of HSLA steel as the research object and analyses the effect of calcium and magnesium addition on the cast microstructure and inclusions. The study can provide a reliable theoretical basis and technical support for the development and application of high heat input welding HSLA steel.

\section{Experiments}

\section{Experimental Materials}

A kind of HSLA steel is designed in this experiment. The components of the steel are obtained by smelting pure iron and adding the corresponding alloy. The components of pure iron and main alloy are shown in Tab.1. Calcium and Magnesium are added simultaneously in the form of Si-Ca alloy and $\mathrm{Mg}-\mathrm{Zr}$ alloy. Other alloys include electrolytic manganese (99.9\%), ferrovanadium (78.6\%), ferrotitanium (99\%), ferroniobium (65.6\%), ferronickel (78.6\%), ferrochromium $(85.5 \%)$ and molybdenum $(76.3 \%)$.

\section{Smelting Equipment and Process}

$\mathrm{Si}, \mathrm{Mn}, \mathrm{P}$ and $\mathrm{S}$ are common elements in HSLA steel, and $\mathrm{C}$ is main element in it. We may add 
some elements in it to deoxidize, such as trace aluminum element and some gas elements $(\mathrm{O}, \mathrm{H}$, $\mathrm{He}$ ), Some of which will be synthetic non-metallic inclusions. According to the actual demand, we can add some other elements, most refers $\mathrm{Nb}, \mathrm{V}$ and $\mathrm{Ti}$, and sometimes includes Mo, $\mathrm{B}$ and Re. Except $\mathrm{Ni}$, the reserves are more abundant in our country. The solid solution, segregation and precipitation produced by microalloy in steel lead to the grain refinement, precipitation strength, recrystallization control and the deformation of inclusions, which play a major role to improve the performance of the steel [3]. Therefore, that is widely used [4]. Some micro-alloying elements such as $\mathrm{Nb}, \mathrm{V}, \mathrm{Ti}$ and so on must be considered to added into the low carbon steel to obtain high toughness [5].

Tab.1 Components of pure iron and main alloys (wt $\%$ )

\begin{tabular}{ccccccccccccc}
\hline Alloy & $\mathrm{C}$ & $\mathrm{Si}$ & $\mathrm{Mn}$ & $\mathrm{P}$ & $\mathrm{S}$ & $\mathrm{Al}$ & $\mathrm{Fe}$ & $\mathrm{Ca}$ & $\mathrm{Mg}$ & $\mathrm{Zr}$ & $\mathrm{Ni}$ & $\mathrm{Cu}$ \\
\hline Pure & 0.0013 & 0.01 & 0.05 & 0.007 & 0.0044 & 0.0013 & 92.6 & $/$ & $/$ & $/$ & $/$ & $/$ \\
iron & & & & & & & & \\
$\mathrm{Fe}-\mathrm{Si}$ & 0.024 & 78.96 & 0.058 & 0.0093 & 0.0037 & 0.24 & 20.24 & $/$ & $/$ & $/$ & $/$ & 0.049 \\
$\mathrm{Si}-\mathrm{Ca}$ & 0.13 & 66 & $/$ & 2.6 & $/$ & 0.15 & $/$ & 31 & $/$ & $/$ & $/$ & 12 \\
$\mathrm{Mg}-\mathrm{Zr}$ & $/$ & 0.0053 & 0.0061 & $/$ & $/$ & 0.0053 & 0.029 & $/$ & 69.68 & 30.12 & 0.15 & 0.0014 \\
\hline
\end{tabular}

We designed a kind of HSLA steel, based on the above principle and absorbing the predecessors's research experiences. The BJ-VIM-5 vacuum induction melting furnace was used in the smelting test of HSLA steel. We designed two furnaces in this experiment, and $5 \mathrm{~kg}$ steel was smelted in each furnace. The actual smelting components corresponding to the design components were shown in Tab.2. The forming oxide element such as $\mathrm{Ca}$ and $\mathrm{Mg}$ were matched with raw materials for steel according to mass percent. The two furnaces in the test were accomplished in the order of no calcium and magnesium addition, $3 \mathrm{wt} \% \mathrm{Ca}$ and $3 \mathrm{wt} \% \mathrm{Mg}$ addition at the same time.

Tab.2 Designed and actual melting chemical compositions of experimental steel

\begin{tabular}{|c|c|c|c|c|c|c|c|c|c|c|c|c|c|c|}
\hline \multirow{2}{*}{ Item } & \multicolumn{14}{|c|}{ The chemical components $(\mathrm{wt} \%)$} \\
\hline & $\mathrm{C}$ & $\mathrm{Si}$ & $\mathrm{Mn}$ & $\mathrm{P}$ & S & $\mathrm{Ni}$ & $\mathrm{Cu}$ & Mo & $\mathrm{V}$ & $\mathrm{Nb}$ & $\mathrm{Cr}$ & Als & $\mathrm{Ti}$ & $\mathrm{N}$ \\
\hline $\begin{array}{l}\text { The design } \\
\text { components }\end{array}$ & $\begin{array}{c}0.06 \\
-0.09\end{array}$ & $\begin{array}{c}0.10- \\
0.20\end{array}$ & $\begin{array}{l}1.45- \\
1.60\end{array}$ & $\leq 0.015$ & $\leq 0.006$ & $\begin{array}{c}0.25- \\
0.35\end{array}$ & & $\begin{array}{l}0.20- \\
0.30\end{array}$ & $\begin{array}{c}0.045- \\
0.055\end{array}$ & $\begin{array}{l}0.01- \\
0.02\end{array}$ & $\begin{array}{l}0.10- \\
0.30\end{array}$ & $\leq 0.01$ & $\begin{array}{c}0.01 \\
-0.02\end{array}$ & $\leq 0.005$ \\
\hline $\begin{array}{l}\text { The actual } \\
\text { components }\end{array}$ & 0.10 & 0.13 & 1.4 & 0.012 & 0.005 & 0.28 & - & 0.202 & 0.047 & 0.015 & 0.19 & 0.007 & 0.016 & l \\
\hline
\end{tabular}

The steps of smelting the experimental steel are as follows.

(1) The raw materials are put into the crucible. We must adopt the principle of tightness below and looseness above in order to make the smelting process go smoothly, when we add the raw materials.

(2) After adding the raw materials, we begin to vacuumize. When the vacuum degree reaches $1.0 \times 10^{-2} \mathrm{~Pa}$, we begin to heat.

(3) We turn up the power gradually in the heating process until the raw materials melt totally.

(4) The argon gas as protective gas is filled in the whole smelting process to prevent the raw materials from oxidating. When the steel boils, we add alloy by a special method.

(5) After adding alloy, we begin to stir it. After refinement for several minutes, we turn off the heating equipment and begin to pour.

(6) After cooling for three hours, the casting mould is taken out.

\section{Preparation of the Metallographic Specimen}

The cylindrical ingot, whose diameter is $60 \mathrm{~mm}$, is got. The specific steps of the cutting plan in the experiment are as follows. 
Firstly, the $10 \mathrm{~mm}$ thickness ingot was cut off along the cross section at the bottom of the ingot. Then, the 1\# sample was got.

Secondly, the ingot was cut along the axis direction which was $20 \mathrm{~mm}$ far from the center of the ingot. Then the crescent $2 \#$ sample was got.

Thirdly, the 1\# sample was cut on both sides of the centerline respectively, which was $5 \mathrm{~mm}$ far from the centerline. Then the $3 \#$ sample, whose width was $10 \mathrm{~mm}$, was got.

Fourthly, the 2\# sample was cut twice along the center section and the places cut along were $10 \mathrm{~mm}$ away from each other. Then the 4\# sample was got.

Finally, the microstructure observation and analysis had been done for 3\# and 4\# samples of each ingot, which were got from wire-electrode cutting. The progress of making the metallographic samples were as follows: rubbing down $\rightarrow$ polishing $\rightarrow$ the corrosion of $4 \%$ nitric acid alcohol solution $\rightarrow$ stoving.
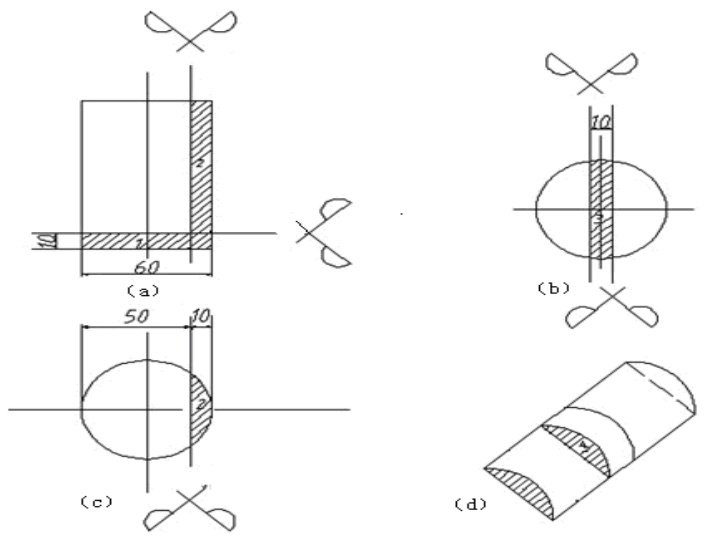

(a)(c) 1\# and 2\# samples (b) 3\# sample (d) 4\# sample

Fig.1 Interception process of metallographic specimen

\section{Effect of Calcium and Magnesium Addition on the Cast Microstructure of the HSLA Steel}
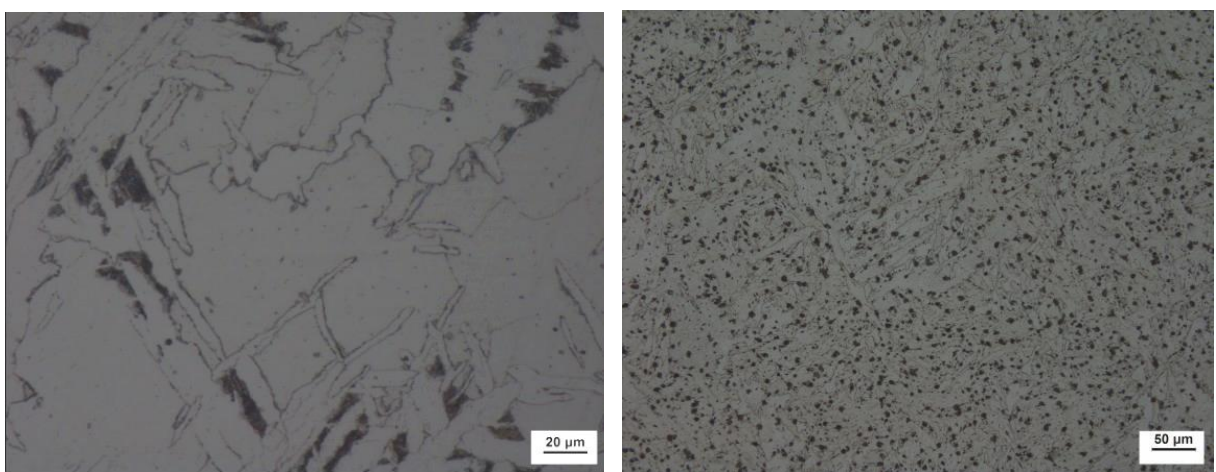

a. the cast metallographic microstructure of the original steel
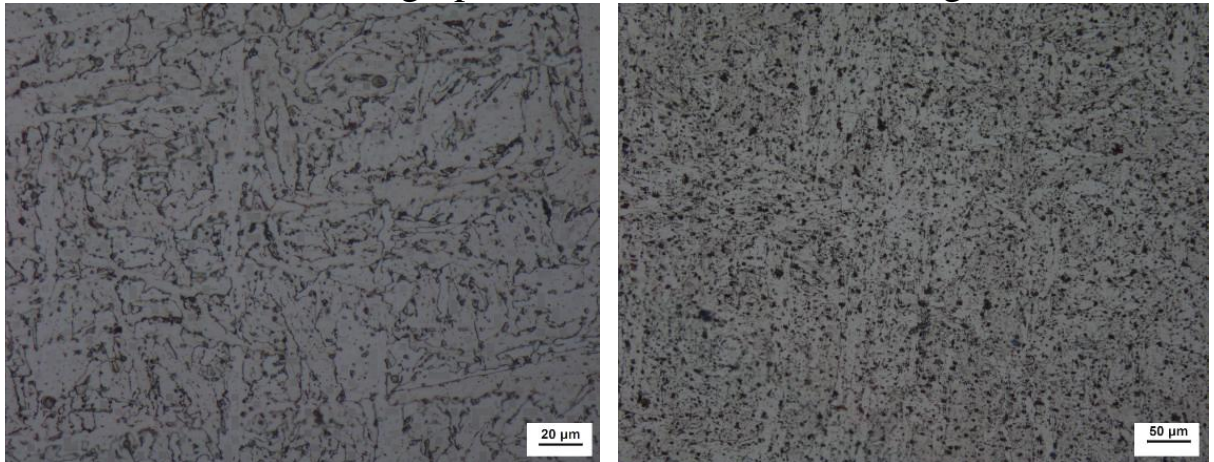

b. the cast metallographic microstructure of the $3 \mathrm{wt} \% \mathrm{Ca}$ and $3 \mathrm{wt} \% \mathrm{Mg}$ experimental steel

Fig.2 Cast microstructure comparison diagrams of each sample 
The prepared metallographic samples zoomed in 200 and 500 times were respectively observed using the OLYMPUS-CK40M optical metallographic microscope. The diagrams of cast microstructure of the HSLA steel were obtained.

The contrast diagrams of the cast microstructure at the bottom of the samples of the HSLA steel were shown in Fig. 1 (a-b), including no calcium and magnesium addition, $3 \mathrm{wt} \% \mathrm{Ca}$ and $3 \mathrm{wt} \%$ $\mathrm{Mg}$ addition at the same time.

\section{Results Analysis}

The microstructures that often can be found in the common steel are bainite, martensite, pearlite, ferrite and so on. We can find that there are some differences in the microstructure among each experimental steel. The cast microstructure is mainly consist of lamellar and acicular ferrite, a small amount of pearlite and bainite. The observation results are tabulated and shown in Tab.3. Compared with the original steel, there are bainites presenting in the experimental steel after adding $3 \mathrm{wt} \% \mathrm{Ca}$ and $3 \mathrm{wt} \% \mathrm{Mg}$ at the same time. Calcium and magnesium oxides as the second-phase particles prevent the growth of the austenite grains by pinning the austenite grain boundaries. According to the pinning force formula of the particles [6], the pinning force to the original austenite grains becomes greater when the number of the particles increases and the size becomes smaller.

Tab.3 Microstructure observation results of cast steel containing $\mathrm{Ca}$ and $\mathrm{Mg}$

\begin{tabular}{cc}
\hline Experimental steel & The observation results of microstructure \\
\hline The original steel & ferrite+ledeburite \\
$\mathrm{Ca} 3 \mathrm{wt} \%+\mathrm{Mg} \mathrm{3wt} \%$ & lath-shaped ferrite +bainite+pearlite \\
\hline
\end{tabular}

\section{Conclusions}

Calcium and Magnesium elements were added into molten steel in the form of Si-Ca alloy and $\mathrm{Mg}-\mathrm{Zr}$ alloy in the experiment. The experiment takes a kind of HSLA steel as the research object and analyses the effect of calcium and magnesium addition on the cast microstructure of the HSLA steel.

The cast microstructure is mainly consist of lamellar and acicular ferrite, a small amount of pearlite and bainite. Compared with the original steel, there are bainites presenting in the experimental steel after adding $3 \mathrm{wt} \% \mathrm{Ca}$ and $3 \mathrm{wt} \% \mathrm{Mg}$ at the same time. Calcium and magnesium oxides as the second-phase particles prevent the growth of the austenite grains by pinning the austenite grain boundaries.

\section{Acknowledgments}

This work was supported by the Liaoning Province Natural Science Fund Project (No. 2014020097), the Project for Liaoning Provincial Scientific Research in University of China (No. L2014475) and the Open Subject Fund of the State Key Laboratory of Rolling and Automation of NEU, China (No. 2009003).

\section{References}

[1]A. Kojima, A. Kiyose, R. Uemori, Super high HAZ toughness technology with fine microstructure imparted by fine particles, Nippon Steel Technical Report. 380 (2004) 2-6.

[2]Y. Tomita, N. Saito, T. Tsuzuki, Improvement in HAZ toughness of steel by TiN-MnS addition, ISIJ Int. 34 (1994) 829-835.

[3]F. Chai, C. F. Yang, H. Su, Effect of magnesium on inclusion formation in Ti-killed steels and 
microstructural evolution in welding induced coarse-grained heat affected zone, Journal of Iron and Steel Research, International. 16 (2009) 69-74.

[4]L.Q. Zhang, Research on high heat input welding alkaline metals micro-alloyed high strength low-alloyed steels, Wuhan University of Science and Technology. (2009).

[5]Y. Li, C.X. Wang, Z.L. Tian, Investigation on microstructure and mechanical properties of a low alloyed ultra-high strength steel, Iron and Steel. 43 (2008) 75-79.

[6]X.G. Qi, M.A. Chen, J.H. Chen, Effect of second-phase particle on austenite HAZ in microalloyed steel, Materials Science and Technology. 13 (2005) 34-37. 